\title{
Assessing Outcomes of Long-Term Research Collaboration
}

\section{ELIZABETH G. CREAMER}

Virginia Polytechnic Institute and State University

\section{ABSTRACT}

This paper explores the link between research collaboration and innovation among faculty, as indicated by a self-reported assessment of the contribution of a co-authored publication to knowledge. Findings challenge the assumption that collaborators are rarely involved in theory development and the practice of crediting only the lead author for the intellectual content of a coauthored publication.

\section{RÉSUMÉ}

Ce mémoire explore le lien entre la collaboration et l'innovation en matière de recherche au sein du corps professoral, d'après une autoévaluation de la contribution d'une publication collective au savoir. Les conclusions mettent en doute la supposition que les collaborateurs participent rarement à la conception de théories de même que la pratique de créditer uniquement l'auteur principal du contenu intellectuel d'une publication comptant plus d'un auteur. 
Elizabeth: It almost sounds like...not piggy backing. You know when children jump over each other's backs ...

Carol: Leapfrog.

Elizabeth: That's exactly the word I was looking for.

Carol: Yeah. Yeah. Yeah. That is exactly right. Like no one is ahead. It's just that the conversation keeps moving. When we trade [manuscripts], it's not like the absence of trust. It's not the presence of correction.

Elizabeth: So this is how knowledge moves forward, in small increments?

Carol: Increments and then sometimes, big fat radical leaps.

The leapfrog metaphor that arose spontaneously during my interview with this prolific author points to a tie between collaboration and quality that has yet to be documented conclusively by research. The metaphor also makes a distinction between two different kinds of learning that lead to innovation; the spontaneous flash of insightthe "big fat radical leaps" - and the small "increments" that describe the inching forward of an idea, often through conversation.

Social constructionists link the learning that occurs when collaboration is deployed as a pedagogical tool in the classroom with the experience of scientists constructing knowledge. They mount the argument that both involve the co-construction of knowledge through dialogue (Bruffee, 1999). Social constructionists might say that learning that arises through conversation is at the heart of the exchange about the leapfrog metaphor. Bruffee (citing Latour \& Woolgar, 1986) would maintain that the exchange describes the most important type of exchange that occurs among scientists. That is the displaced conversation scientists engage in through writing and the exchange of manuscripts. This fits with a definition of collaboration, not as the sharing of work, but as a social inquiry practice that promotes learning (Creamer \& Lattuca, in progress).

The exchange with this researcher offers a reply to one of the questions that permeates the literature about collaboration. That is: is there a significant relationship between collaboration, enhanced 
quality, and innovative new insight? While the assumption is that there is a positive relationship, the empirical literature has failed to demonstrate conclusively a significant link between collaboration and enhanced faculty productivity (Austin, 2001). Acceptance rates are higher for publications with multiple authors than for singleauthored ones, but citations, a traditional measure of quality, are not (Smart \& Bayer, 1986). Prolific researchers collaborate more than their less productive colleagues, but it is not clear whether collaboration leads to increased productivity or whether academics who are collaborative by nature are more productive (Austin \& Baldwin, 1991).

There has been little empirical research about the outcomes of different types of collaborative arrangements (Smart \& Bayer, 1986). Austin and Baldwin call for more research on this topic when they note: "More systematic research on the benefits and outcomes of collaboration is essential" (1991, p. vi). Similarly, Lattuca argues that the intellectual outcomes of interdisciplinary scholarship have been left "virtually unexamined" (2001, p. 50). Cataloguing the intellectual outcomes of collaborative scholarship offers academic administrators, department heads, and members of promotion and tenure committees ideas about how to develop a systematic framework to evaluate the quality of a publication. It also will acquaint collaborators with a variety of different ways to approach collaboration.

This article explores the link between collaboration and innovation by distinguishing different types of intellectual outcomes identified by long-term research collaborators. Intellectual outcomes are defined as the perceived contribution of a joint publication and/ or project to scientific knowledge. Any statement that reflected a judgment about the recognition, quality, impact, or receptivity of colleagues to a co-authored publication was interpreted as a reflection of an intellectual outcome. These also include statements about the impact of the collaboration on productivity or output. 


\section{REVIEW OF RELEVANT LITERATURE}

Innovative work in the academic arena is marked by theory development or the re-conceptualization of theoretical and methodological paradigms that have become entrenched in an academic field. This is not generally considered to be the kind of work that is accomplished through collaboration. Theory building has been cast as an activity most commonly initiated by a solitary scholar in an academic field where consensus has yet to coalesce about the central theoretical and methodological paradigms (Austin \& Baldwin, 1991). The highest rates of research collaboration are found among faculty in high-consensus fields, such as physics and chemistry, where there is agreement about the central paradigms and where it takes the form of theory testing (Austin \& Baldwin). The ability to establish a clear division of labour and ease of communication facilitated by shared language and agreement about core concepts are among the reasons why research collaboration is a more common practice in highconsensus than in low-consensus fields.

Lattuca (2001) links collaboration and learning by identifying the professional and intellectual outcomes faculty informants attributed to interdisciplinary research and teaching. Professional outcomes include tangible rewards such as advancement in rank, conference presentations, and publications. Intellectual stimulation, growth, learning, and a new perspective on a disciplinary problem or about the nature of scholarship are some of the intellectual outcomes Lattuca identified. The more prolonged and intense the interactions with different disciplinary perspectives, the more likely informants were to report questioning the epistemological and methodological assumptions of their own academic discipline (Lattuca, 2001).

Name ordering conventions often short-change collaborators (Tescione, 1998). Collaborators who produce self-reflexive accounts 
frequently point to the struggle not only to represent more than one voice in a text, but to find ways to acknowledge the contribution as equal (e.g. Gottlieb, 1995; Kochan \& Mullen, Mullen \& Kochan, 2001). Some co-authors who have experimented with unconventional approaches to listing their names (see Kochan \& Mullen, Mullen \& Kochan), have had their efforts erased by style conventions and the practices utilized by citation databases.

\section{Sample}

\section{METHOD}

The interview sample contains members of 19 collaborative pairs, where one or both members of a pair or team were interviewed $(\mathrm{N}=31)$. Each pair includes at least one member who holds the ranks of associate or full professor at a research university and has published a career total of a minimum of 21 refereed journal articles and/or book chapters. The majority of participants (19 of 31 or $61 \%$ ) have published 50 or more chapters or referred journal articles. Additional descriptive information about the participants is presented in Table 1 .

Participants include 13 pairs who earned doctorates in the same aca-demic discipline (archeology, anthropology, biochemistry, communications, economics, geology, microbiology, physics, psychology [2 pairs], sociology [2 pairs], special education) and 6 pairs who earned doctorates in different academic disciplines (political science-economics, educational policypsychology, education- psychology [2 pairs], anthropologyEnglish, English-history).

Unlike the hierarchical, junior-senior/mentor-apprentice configuration that seems ubiquitous in the literature dealing with collaboration, members of most of the pairs could be described as career-equal or career symmetrical (13 of 19 pairs). In other words, the majority of participants did not describe significant difference in career age or stage or characterize the relationship as one 
involving a mentoring or a hierarchical relationship. Participants are identified by pseudonyms.

Table 1

Descriptive Information About the Participants ( $=31)$

Year of Terminal Degree

$\begin{array}{lrr}1969 \text { \& Before } & 7 & (23 \%) \\ 1970-1979 & 11 & (35 \%) \\ 1980-1989 & 12 & (39 \%) \\ 1990 \& \text { After } & 1 & (3 \%)\end{array}$

Gender

$\begin{array}{lll}\text { Female } & 15 & (48 \%) \\ \text { Male } & 16 & (52 \%)\end{array}$

Academic Rank

Associate

Professor 25

Other

Discipline of Doctorate

Bio/Physical Sciences 5

Education

Humanities

Social Sciences

Career Journal Article Productivity

Less than 21

$21-49$

10

50 or more

19

(61\%)

\section{Data Collection}

Multiple sources of data were collected for each of the collaborative pairs. These include: (a) a one-on-one interview with one or both members of the pair, (b) a copy of their vita which I used 
to assess publication levels, and (c) document analysis of selected co-authored publications when they could inform the interview and/ or analysis.

The interview. After collecting background material, including a copy of a curriculum vita and a signed informed consent form, a semi-structured protocol was used as a guide for the interview. The protocol contained questions relating to the dynamics and outcomes of a specific collaborative relationship. The interviewer attempted to create a climate for a rather free-flowing conversation. The interview questions were not asked in the exact same order, but at a time where they seemed to fit in the flow of the conversation. Interviews normally lasted between 45 and 90 minutes. The interviews were tape recorded and transcribed verbatim.

The focus of this paper is responses to the first question in the interview protocol. Participants were asked to describe the nature of the work they had done with a collaborator who they had already identified and what they saw as the primary outcomes of the work they accomplished together. While respondents were not asked if their work was theoretical, it was generally in the context of their responses to this first question in the interview that this information emerged.

Documents. Participants frequently made references to a specific publication or document during the course of the interview. In some cases, the reference was to a publication that provided insight into some aspect of the collaborative process, such as authorship guidelines. Several of the participants had written a personal account of the experience of collaborating or about some aspect of the collaborative relationship, such as mentoring. Selected publications or documents that a participant identified by name during the interview were reviewed as a way to triangulate findings and add context to the understanding of the collaborative relationship, process, and its outcomes. 


\section{Data Analysis}

Data were analyzed using the constant comparative method (Strauss \& Corbin, 1994). The process began with open coding, expanded to clarification of the definition of codes and elimination of codes that did not prove significant across cases, moved to axial coding that identified connections between categories, and ended with a set of theoretical propositions. Data collection, analysis, and verification occurred simultaneously, utilizing an iterative process. Given the complexity of data, interviews were read and coded many times over a number of years until a satisfactory coding scheme and method of analysis were developed.

Trustworthiness. A number of strategies were used to enhance the trustworthiness of the findings. These included (a) triangulation by using multiple sources of data, (b) thick description, and (c) member checks. Interviews with a second member of a pair afforded the opportunity to test the accuracy of interpretations and to follow-up on responses from the initial interview that seemed unclear or contradictory.

\section{FINDINGS}

Four categories of responses emerged from what participants identified as the primary intellectual outcomes of collaborative research projects. These are: (a) efficiencies of practice, (b) nuances in thinking, (c) coming up with the big picture, and (d) challenging the gospel. The full context of all of the available information was used to make a judgment about which single category each pair was most closely aligned. The categories overlap, suggesting a continuum of outcomes.

Table 2 provides a definition for each of the four categories of intellectual outcomes. Table 3 provides a more detailed list of the distinguishing characteristics of each of the categories of intellectual outcomes. 
Table 2

Categories and Definitions of Intellectual Outcomes Identified by Long-Term Research Collaborators ( $\mathrm{N}=19$ pairs)

\section{Category of Outcome}

Efficiencies of Practice

( $\mathrm{n}=7$ pairs)

\section{Definition}

Complete an investigation that otherwise would be difficult or impossible to accomplish.
Nuances in Thinking

$(\mathrm{n}=5$ pairs)
Advance a more nuanced interpretation of a phenomenon or theoretical position without fundamentally altering a commitment to its basic constructs.
Coming up with the Big Picture

( $\mathrm{n}=3$ pairs)
Integrate distinct areas of expertise, even within the same academic discipline, to create a more allencompassing explanation of a phenomenon than had been previously available in the literature.
Challenging the Gospel ( $\mathrm{n}=4$ pairs)
Challenge mainstream disciplinary theories or methods. 
Table 3

Distinguishing Characteristics of Categories of Intellectual Outcomes Identified by Long-Term Research Collaborators

Category of Outcome

Efficiencies of Practice

\section{Distinguishing Characteristics}

Time-saved from a clear division of labour.

Additional publications.

When theoretical, application of theory to a new population or setting.

Add insight to theory without challenging its core assumptions.

Create new theory or substantially revise an existing one.

Integrate or synthesize independent and sometimes competing explanations to create theory.

Aim to reach audiences in more than one discipline.

Experiment with new methodologies or inquiry paradigms.

Experience adverse feedback from colleagues.

Voice sense of risk-taking or experimentation.

On some occasions, leave differences of opinion or interpretation unresolved. 


\section{Efficiencies of Practice}

With 7 of 19 pairs of research collaborators appearing in this category, efficiencies gained through combined efforts is the outcome most frequently mentioned by long-term collaborators. A key indicator of affiliation with this group was an emphasis on the enhanced productivity made possible by the joint/team effort. This is the only category where members emphasized that the project could be completed more quickly or readily because it was collaborative.

Although this is the collaborative pattern most frequently captured in the literature, it is the one in which participants were least likely to associate with learning or innovation. Members of this group emphasized that the collaboration gave them the opportunity to accomplish something they could not have done alone. This is the only category where project goals were often accomplished with minimal proximity and relatively low levels of substantive dialogue or exchange.

A statement made by a participant, Lucian, an economist well advanced in his career, who collaborated with Kevin, a political scientist who is 25 years his junior, reflects one of the key indicators of affiliation with this category. Lucian observed, "I was able to write things that I would never have been able to do by myself." Lucian bought the ability to frame the work in the literature, and Kevin brought advanced statistical skills to the six journal articles they co-authored in a five-year period. Lucian reflected an assessment of the impact of a co-authored article when he said "the signature piece of our collaboration ... has received considerable attention and a lot of interest from other scholars."

Marvin, a biochemist in a medical school who studies one aspect of the structure of a ribosome with a male colleague at another medical school in the same state system, reiterated the same themes. Reflecting on the project outcomes, he said [it was] "definitely beneficial to both of us because we have both been able to do things that the other one either couldn't do or would have a 
hard time doing ... you can get things done much more easily and much more quickly."

\section{Nuances in Thinking}

The group with the second largest number of participants, members of 5 of 19 pairs described the intellectual outcomes of their collaborative ventures in ways that clearly indicated learning. These participants attributed advances in thinking or sharpening thinking about a complex issue as the primary outcome of their collaboration. Members of this group were involved in theory testing or theory development. The collaboration was perceived to contribute to quality by creating the context to reach a more layered understanding of a theoretical perspective, without causing the collaborators to abandon the perspective or to significantly reconsider its core constructs. Members of this group did not pursue collaboration primarily for the purpose of elevating publication counts.

A member of a pair in this category, Muriel, observed how collaboration helped move her thinking forward. She characterized her collaborative work as having a synthetic quality, when she noted, "It is really better than one of us could have written individually." Muriel's words reflect a careful assessment of the costs and benefits of collaboration:

I don't do collaboration just to do it. It is too much work. It takes a lot of time. It can be very frustrating ... I don't seek out collaboration unless it pushes forward what I do in some ways ... I was trained as sort of an independent, individualistic academic. She was less so because she was in psychology. I don't have that kind of collaborative background. So, the collaborations have to be something that is really valuable; something that really moves my thinking forward. (Muriel, Educational Policy Studies)

While it comes at the cost of efficiency and a proclivity to work alone, Muriel collaborates for reasons of learning. She 
believes that it advances her thinking and improves the quality of her work.

A pair of psychologists who are also a couple, Diane and Mark, identified theory development as an outcome of their collaboration. Trained in the same doctoral program at the same time, Diane became a clinical psychologist, while Mark developed expertise in the psychology of personality. Diane described how she and Mark developed a theoretical perspective through on-going conversation over a period of years:

We have actually, over the years, developed a couple of basic theoretical models that have been pretty widely picked up. I guess I think of that as creative work, or at least it comes out of the literature. We didn't make it up whole cloth. That kind of thing, you don't just sit down and say, okay, I am going to come up with a theory. It develops over multiple conversations over the period of years and also, I think, out of the process of writing in the first place. (Diane, psychologist)

Diane's reference to the theoretical perspective being "pretty widely picked up" reflects an evaluation of its impact. It means that she is aware that other scholars have adopted the perspective.

\section{Coming Up With the Big Picture}

Members of 3 of 19 collaborative pairs identified the ability to merge distinct areas of expertise to come up with the big picture as the primary intellectual outcome of their joint endeavours. There are clear ties in this group between collaboration and the outcomes of learning and innovation. A key distinction of the members of this group is that not only were all involved in theory development, but all did so by integrating independent, sometimes competing, interpretations. In constructing the "big picture" collaborators in this group seem to have been able to move their thinking one step further than those belonging to the group I have called, "nuances in thinking." 
A pair of structural geologists, Susan and Leo, illustrate the intellectual challenge of reconciling competing explanations. Striving for an explanation of the development of mountain chains, Susan and Leo have spent decades studying an area in California that is the only place in the world where the "hard" rocks that are her specialty and the "soft" rocks that are his specialty are found side-by-side. A couple, Susan and Leo do not think alike and joke frequently about how the other's explanation is misguided. Noting the synthetic outcomes of their work, Leo said:

Working on similar problems, we can combine our information. Instead of just having a little, small piece of the project, we can have a much bigger project or paper. Merging information, you can make a synthesis where one person has one part of the puzzle and the other part is in another person's area. You can come up with the big picture. (Leo, geologist)

A pair of paleo-anthropologists who study prehistoric remains, Alex and Victor, mirrored a very similar process of creating an overarching theoretical explanation by combining specialized areas of expertise. With doctorates from the same department, but in cohorts separated by a few years, Victor's expertise is in fossil bones; Alex's expertise is in stone implements. After several summers of fieldwork in a remote location in Southeast Asia, they developed a theoretical explanation for the extinction of a particular species of dinosaur. They achieved this outcome by combining Victor's knowledge of "bones" and Alex's knowledge of "stones" and interpreting the evidence as it appeared side-by-side in different layers of sediment. In a sense, they built their evidence, layer by layer, just as they developed a theoretical explanation by interpreting historically situated layers of bones and stone implements. 


\section{Challenging the Gospel}

Members of 4 of 19 pairs explicitly framed key project outcomes as challenging prevailing disciplinary paradigms. A distinguishing characteristic of members of this group is that they reported experimenting with a new methodology or inquiry paradigm during the process of collaborating. Members of this group were the only participants to mention risk-taking and/or negative feedback from colleagues. All of the collaborators in this group aimed to be interdisciplinary by virtue of their ambition to reach audiences in more than one academic discipline.

All of the members of this group framed the outcomes of their work as innovative because they challenged conventions of their home discipline. Steven, the principal investigator of a longitudinal study of immigrant youth, illustrates how this critique is embedded in a deliberate strategy to look at a problem from multiple angles. He described how some of the decisions he has made about how to pursue a collaborative, team-based research agenda is grounded in dissatisfaction with some aspects of his training:

In the clinical setting I was working in [during graduate school], I was very, very disillusioned by what I saw going on ... I only for a short time, entertained the idea which was pretty dominant in psychology, at the time, that you pick a particular problem and you just become incredibly focused on that... and that you take a particular point of view. I got the idea that you need to attack problems from many different directions. (Steven, psychology)

Framed by an intentional approach to look at research problems from different disciplinary angles, these collaborators' research ultimately led them to challenge a widely held disciplinary axiom.

A specialist in Japanese history, Herb experienced a paradigm shift during the course of collaborating that was so profound that it caused him to reconsider whether to remain focused on his home disciplines. For over 25 years, Herb has collaborated with a 
colleague, Hito, who though Japanese by birth has spent most of his career studying English literature. Their work has focused on the cultural history of Japan. Over the course of their interactions with a network of like-minded colleagues, Herb and Hito grew to have serious reservations about the organization of area studies as separate academic disciplines or programs. This is the topic of their most recent co-authored book.

Herb clearly conceptualized the outcomes of this collaboration in terms of his own learning. He described the transformation in his thinking when he said,

I think I have learned more from this particular collaboration than I have from others ... I find that it has certainly affected my own personal work, the work that I do by myself in a way I wouldn't have anticipated ... I've learned that I am not simply a specialist in a certain segment of Japanese history and that this stuff really has to always be thought of in much broader terms. (Herb, History)

Herb described the personal gain of learning to think in "much broader terms."

\section{DISCUSSION}

Participants clearly perceived a strong positive relationship between collaboration and learning and innovation. The majority of participants pointed to the synthetic quality of collaboration, or its impact, on the quality of the work produced. This near universal sentiment was phrased in one of two ways: "I couldn't have done it alone." or "What we produced together is better than either of us could produce alone." The second statement communicates a strong belief in the idea of synergy - that in successful collaborations, the total is greater than the sum of the parts. In these cases, the work produced collaboratively is a unique co-construction of knowledge that cannot be reduced to the sum of the distinct skills and expertise of the collaborators (John-Steiner, Weber, \& Minnis, 1998).

The Canadian Journal of Higher Education

Volume XXXIV, No. 1, 2004 
Participants who characterized their work as theoretical can be found in each of the four categories of intellectual outcomes. There are differences, however, in their experiences with theory development. Members of the first group, "efficiencies of practice," were involved in the application or extension of a theoretical framework to different populations or settings. Members of this group were unlikely to characterize their work as innovative. Members of the second group, "nuances in thinking," characterized their work as adding significant insight to a theory without challenging its central assumptions. Members of the third group, "coming up with the big picture," found a way to synthesize competing explanations that derived from their different areas of expertise to come up with an original and more all-encompassing explanation of a phenomenon than had previously been available. Members of the fourth group, "challenging the gospel," took yet a fourth approach to theoretical work. Members of this group reached different conclusions about a theoretical or paradigmatic issue that they could not necessarily reconcile. In the process of confronting different interpretations, members of this group experimented with methods, and sometimes inquiry paradigms, that were unfamiliar to them.

A number of characteristics of members of the sample may explain why their collaborative work involved theory development to a much greater extent than the literature anticipates. The first is that the sample largely contained non-hierarchical dyads. The majority of pairs consisted of senior academics that brought considerable expertise and experience to a topic, generally from distinct but complementary areas of expertise. Secondly, the longevity of the collaboration provided the context for either prolonged engagement focused on a single line of inquiry, or about a series of loosely related topics that, nevertheless, were united by a common thread.

Most of the participants in the study described the process of collaboration in ways that differ dramatically from the picture of collaboration routinely captured in the research literature. The high and on-going level of interaction and relatively fluid division of labour 
due to comparable skill levels described by many of the participants differ substantially from the hierarchical division of labour that is often taken as the normative approach to collaboration.

\section{CONCLUSIONS}

Findings from this research provide preliminary support for a number of conclusions about the relationship between collaboration, learning, and innovation. Findings support the idea that long-term collaboration is associated with both quality and innovation, but extend the idea by demonstrating that innovation can take a number of different forms and be accomplished in a number of different ways. Secondly, contrary to the dominant view presented in the research literature, many long-term collaborators were involved in what they characterized as theory development. Finally, while supporting the idea that distinct skills and expertise contribute to innovation, findings suggest that innovation is just as likely to characterize the work of collaborators from the same academic discipline as collaborators trained in different academic disciplines. Additional research with a larger sample of collaborators is needed to confirm these findings, as well as to explore possible disciplinary differences in what academics mean when they characterize their work as theoretical.

The findings presented here offer preliminary support for a framework to assess the quality of a publication in terms of its contribution to knowledge. Participants reported a process that can be interpreted as a ladder of intellectual outcomes that has atheoretical work as its first rung; moves to theory testing or confirmation by the application of a theoretical perspective to a new setting or population as its second rung; advances to making significant modifications or refinements to theoretical assumptions; and ends at the top rung with providing alternative theoretical conceptions that challenge prevailing disciplinary assumptions. In this outcome-based approach to evaluation, knowledgeable peers could confirm the assessment of 
the contribution of the publication to the state of knowledge in the field at the time. These ideas need to be pursued within the context of the larger body of work about evaluating the professoriate (see, for example, Braxton, Luckey, \& Helland, 2002; Glassick, Huber, \& Maeroff, 1997).

The outcome-based approach offers no remedies for awarding credit when individual contributions to a collaboration are not comparable. Examples presented throughout the paper add credibility, however, for the claim that mature collaborators with comparable levels of expertise can be co-equals in the production of interpretive, theoretical work and thus are justified in laying claim to comparable credit or recognition. Some consider any attempt to distinguish an individual's contribution as antithetical to the spirit of collaborative efforts (Hafernik, Messerschmitt, \& Vandrick, 1997).

While it is challenging to make the subtle distinction between how a publication advances an individual's knowledge and/or skills and how it advances knowledge in the field, the distinction is an important one. A positive experience with collaboration can advance an individual's skills and knowledge and contribute to faculty development and vitality without making a significant contribution to the field. A judgment about the quality of a piece of work or how innovative it is ultimately rests on a subjective comparison to the state of knowledge in a field.

\section{References}

Austin, A.E. (2001). Reviewing the literature on scholarly collaboration: How we can understand collaboration among academic couples. In E. G. Creamer \& Associates, Working equal: Academic couples as collaborators (pp. 130-145). N.Y.: RoutledgeFalmer Press.

Austin, A.E., \& Baldwin, R.G. (1991). Faculty collaboration: Enhancing the quality of scholarship and teaching. ASHE-ERIC Higher Education Report No. 7. Washington, DC: George Washington University, School of Education and Human Services. 
Braxton, J.M., Luckey, W., \& Helland, P. (2002). Institutionalizing a broader view of scholarship through Boyer's four domains. ASHE-ERIC Higher Education Report: Volume 29, No. 2. Wiley Periodicals, Inc.

Bruffee, K.A. (1999). Collaborative learning: Higher education, interdependence, and the authority of knowledge (Second Edition). Baltimore, MD: Johns Hopkins University Press.

Creamer, E.G., \& Lattuca, L.R. (in progress). Advancing faculty learning through interdisciplinary collaboration. New Directions for Teaching and Learning. San Francisco, CA: Jossey-Bass.

Creswell, J.W. (1985). Faculty research performance: Lessons from the sciences and social sciences. ASHE-ERIC Higher Education Report No. 4. Washington, D.C.: Association for the Study of Higher Education. ED 267677.

Glassick, C.E., Huber, M.T., \& Maeroff, G.I. (1997). Scholarship assessed: Evaluation of the professoriate. San Francisco, CA: Jossey-Bass Publishers.

Gottlieb, A. (1995). Beyond the lonely anthropologist: Collaboration in research and writing. American Anthropologist, 97(1), 21-25.

Hafernik, J.J., Messerschmitt, D.S., \& Vandrick, S. (1997). Collaborative research: Why and how? Educational Researcher, 26(9), 31-35.

John-Steiner, V., Weber, R.J., \& Minnis, M. (1998). The challenge of studying collaboration. American Educational Research Journal, 35(4), 773-783.

Kochan, F.K., \& Mullen, C.A., Mullen, C.A., \& Kochan, K.F. (2001). Collaborative authorship: Reflections on a briar patch of twisted brambles. Teachers College Record (http://www.tcrecord.org/Content.asp?/ ContentID-10661).

Latour, B., \& Woolgar, S. (1986). Laboratory life: The social construction of scientific facts (second edition). Princeton, NJ: Princeton University Press.

Lattuca, L.R. (2001). Creating interdisciplinarity: Interdisciplinary research and teaching among college and university faculty. Nashville, TN: Vanderbilt University Press.

Smart, J.C., \& Bayer, A.E. (1986). Author collaboration and impact: A note on citation rates of single and multiple author articles. Scientometrics, 10(5-6), 298-305.

Strauss, A., \& Corbin, J. (1994). Grounded theory methodology: An overview. In N.K. Denzin \& Y.S. Lincoln (Eds.), Handbook of qualitative research (pp. 273285). Thousand Oaks, CA: SAGE Publications.

Tescione, S.M. (1998). A woman's name: Implications for publication, citation, and tenure. Educational Researchers, 27(8), 38-42. 